\title{
O QUE PODEMOS APRENDER COM OS AUTISTAS: A EXPERIÊNCIA CLÍNICA DE UMA PROFESSORA DO ENSINO FUNDAMENTAL E UM ALUNO AUTISTA
}

\author{
WHAT WE CAN LEARN FROM THE AUTISTS: THE CLINICAL EXPERIENCE OF A FUNDAMENTAL \\ TEACHER AND AN AUTISTIC STUDENT \\ LO QUE PODEMOS APRENDER DE LOS AUTISTAS: LA EXPERIENCIA CLÍNICA DE UNA \\ PROFESORA DE EDUCACIÓN BÁSICA Y UN ESTUDIANTE AUTISTA
}

\section{Patrícia Fernandes de Carvalho*}

\begin{abstract}
RESUMO
Este artigo tem como objetivo refletir o conceito de inclusão sob duas perspectivas: a educação inclusiva e o direito à educação especial, garantida por lei na Constituição Brasileira de 1988, e a inclusão, segundo o conceito psicanalítico, considerando o que podemos aprender com os autistas em uma experiência escolar. Para tanto, buscaremos, nos estudos de Freud, o conceito de impossibilidade na esfera do educar. Também usaremos as referências psicanalíticas de orientação lacaniana que demonstram, na estrutura autística, a importância no apoio do duplo na constituição de uma borda e construção de um Outro sob medida para o sujeito. Este texto apresenta vinhetas clínicas narradas por uma professora do ensino fundamental, demonstrando o que os autistas nos ensinam.
\end{abstract}

Palavras-chave: Educação inclusiva. Alfabetização. Autismo.

\begin{abstract}
This article aims to reflect the concept of inclusion on two perspectives: inclusive education and the right to special education, guaranteed by law in the Brazilian Constitution of 1988, and the inclusion according to the psychoanalytic concept; considering what we can learn from autism in a school experience. For this, we seek in Freud's studies the concept of impossibility in the education boundaries. For that, we will use the psychoanalytic references of Lacanian orientation, which demonstrate in the autistic structure, the importance of the support of the double in the constitution of a border and in the construction of an Other tailored for the subject. This article presents clinical vignettes narrated by an elementary school teacher, demonstrating what autists teach us.
\end{abstract}

Keywords: Inclusive education. Literacy. Autism.

\footnotetext{
* Mestra em Educação com Orientação em Gestão de Inovações Curriculares pela USAL, Buenos Aires; especialista em Abordagem Pscicanalítica do Autismo e Suas Conexōes (Instituto de Educação Continuada da Pontifícia Universidade Católica de Minas Gerais - IEC-PUC MINAS), especialista em Alfabetização e Letramento (Ipemig), especialista em Educação Inclusiva (Ipemig), graduada em Pedagogia pela Universidade Federal de Minas Gerais (UFMG). Endereço: Rua Pitangui, 4142, casa - Pompeia, Belo Horizonte-MG, Brasil. CEP: 30280-292. E-mail: patriciacarvalho.lima@hotmail.com.
} 


\begin{abstract}
RESUMEN
Este artículo tiene como objetivo reflexionar el concepto de inclusión desde dos perspectivas: educación inclusiva y el derecho a la educación especial, garantizado por ley en la Constitución brasileña de 1988, y la inclusión, de acuerdo con el concepto psicoanalítico, considerando lo que podemos aprender de los autistas en una experiencia escolar. Por lo tanto, buscaremos en los estudios de Freud el concepto de imposibilidad en el ámbito de la educación. Asimismo, utilizaremos las referencias psicoanalíticas de orientación lacaniana que demuestran, en la estructura autista, la importancia en el apoyo del doble en la constitución de un Otro hecho a medida. Este artículo presenta viñetas clínicas narradas por una maestra de escuela primaria, que demuestran lo que los autistas nos enseñan.
\end{abstract}

Palabras clave: Educación inclusiva. Alfabetización. Autismo.

\title{
1. INTRODUÇÃO
}

o compreender a relação humana como pressuposto básico da relação
pedagógica, entendemos que a educação tem como um de seus propósitos
o endereçamento da palavra ao outro. A ferramenta por excelência da educação é a palavra que o adulto dirige a um indivíduo. Educação se constitui em fazer marcas, em produzir significados com base nos significantes, sendo a palavra o principal instrumento dessa marca. De acordo com a Lei de Diretrizes e Bases da Educação Nacional (Lei nº 9.394, 1996), em seu artigo primeiro:

Art. $1^{\circ}$ A educação abrange os processos formativos que se desenvolvem na vida familiar, na convivência humana, no trabalho, nas instituições de ensino e pesquisa, nos movimentos sociais e organizações da sociedade civil e nas manifestações culturais.

Na concepção da esfera política, a educação é um processo formativo, posto em prática em diversos âmbitos sociais, inseparável da convivência humana, mas, prioritariamente, é um produto escolar. De acordo com esse ponto de vista, a educação obtém o lugar de bem primário, de capital cultural acessível a todos, porém com um resultado diferenciado para cada aluno.

Como nos advertiu Freud em dois de seus trabalhos: Prefácio à "Juventude Desorientada”, de Aichhorn (Freud, 1925/1980) ' e Análise terminávele interminável (Freud, 1937/1980), governar, educar e analisar são os ofícios impossíveis. Como operar com essa impossibilidade do educar, diante o compromisso de ensinar a todos da mesma maneira e o imperativo de vencer os manuais pedagógicos?

1 A primeira data indica o ano de publicação da obra, e a segunda, a edição consultada pelo autor, a qual somente será pontuada na primeira citação da obra no texto. Nas seguintes, será registrada apenas a data de publicação original. 
Estamos em uma época de padronização em que o indivíduo é legislado por uma política da igualdade que segue a exigência de tratar a todos como iguais, como nos apresenta Yanet (2018) em seu artigo O império do Um: diálogo com educadores a propósito da educação inclusiva.

Relembrando o que nos advertiu Freud sobre os ofícios impossíveis, a educação se torna um desses trabalhos, no ponto em que não controlamos o efeito da intervenção no outro, não controlamos o efeito das palavras no outro. Para tanto, adverte para a impossibilidade de educar. Segundo o pessimismo freudiano, "Se pode estar seguro de chegar a resultados insatisfatórios" (Freud, 1937, p. 265)

Segundo o que alguns teóricos denominam de "pessimismo" freudiano, Lacan toma esse substantivo e leva para a lógica e para os discursos, propondo que a psicanálise opere com o impossível no campo dos discursos. "A impossibilidade, como substantivação do modo lógico aristotélico, o impossível, é uma categoria usada por Lacan no exame de diferentes tipos de problemas, tanto teóricos quanto clínicos" (Perez, 2012, p. 202).

Diante desse conceito de impossibilidade de educar, faz-se necessária a organização do contexto de aprendizagem, escolhendo bem as estratégias de ensino adequadas a cada situação. Considerando que a prática educacional ocorre prioritariamente na instituição escolar, acreditamos que, para ampliar e aprofundar a busca pelo êxito, devem-se trabalhar criticamente as formas de se pensar o campo educacional.

A educação inclusiva e o direito à educação especial, garantida na Constituição Federal de 1988, prevê, no artigo 206, inciso primeiro, igualdade de condições para o acesso e permanência na escola. Ela preconiza o discurso da inclusão escolar, de tratar a todos como iguais, outorgando uma naturalização da diferença. As crianças com Transtorno do Espectro Autista (TEA) são situadas na definição de "necessidades especiais", por apresentarem dificuldade de interação social, dificuldade de comunicação e por manifestarem padrōes estereotipados de comportamento.

Este artigo terá como objetivo abordar e compreender a experiência de inclusão escolar em um caso clínico com uma criança autista, em decorrência de síndrome do X-frágil, assim como esclarecer o autismo e suas necessidades especiais descritas nas leis e manuais próprios. Para tanto, tomando como base a vivência escolar dessa criança no período da alfabetização, procura-se entrelaçar fragmentos da prática pedagógica à teoria psicanalítica de orientação lacaniana. 


\section{OS IMPASSES DA INCLUSÃO: INCLUSÃO PARA TODOS X INCLUSÃO DO SINGULAR}

As escolas regulares têm recebido uma parcela crescente de alunos diagnosticados com TEA. Além de alunos autistas, o espaço educativo recebe alunos com transtornos comportamentais, pedagógicos, entre outros. A sala de aula se torna um "ambiente terapêutico" ou lócus de pesquisas diversas, onde aflora nos atores sociais suas demandas e peculiaridades.

Em O mal-estar na civilização, Freud (1929/1981) enfatiza que a educação não prepara as crianças para enfrentar a vida. Tomados por uma vontade inconsciente de moldar as crianças, de acordo com o imaginário de perfeição, os professores tentam o impossível, no sentido pedagógico, pretendendo que a criança venha a repetir as verdades de uma teorização.

Ao afirmar que a educação não prepara para a vida, nesse mesmo texto, Freud (apud Teperman, 2014), acrescenta que ela, a educação, comporta-se como se estivesse equipando pessoas para uma expedição polar, vestidas com trajes de verão e portando mapas dos lagos italianos. Dessa maneira, o ato educativo se configura na passagem da pura satisfação das pulsões para o registro simbólico, em que as marcas das inscrições operam por meio da palavra. Educação se constitui em fazer marcas, em produzir significados, sendo a palavra o principal instrumento dessa marca.

Mas realmente conseguimos expressar aquilo que queremos dizer? Até que ponto controlamos ou percebemos as marcas que fazemos? Relembrando o que nos advertiu Freud sobre os ofícios impossíveis, a educação se torna um desses trabalhos, no ponto em que não controlamos o efeito da intervenção no outro, não controlamos o efeito das palavras no Outro. Para tanto, estabelece a impossibilidade de educar.

Como foi dito anteriormente, a escola é a instituição educativa que, por vias legais, pelas políticas públicas para todos, possibilita o acesso de alunos autistas nas instituições públicas e privadas de todo o País.

Segundo Yanet (2018), “Toda a política da igualdade imperante desde os tempos clássicos se apoia nesta inspiração: tratar a todos como Um, ou, ao menos, invocar Uma legislação para muitos. Assim, dizer todo e Um (com maiúscula) em um sentido, é a mesma coisa”.

De acordo com Santiago (2018), "Caso contrário, um ideal igualitário de tal envergadura pode promover segregação e contribuir para neutralizar, com suas normas, justamente o que singulariza os diversos sujeitos" (p. 15). 
A inclusão que considera o diferente vai trabalhar na questão de sua singularidade, precavendo-se para não seguir a tendência da naturalização, em que há o impulso de anular o diferente. É nesse ponto que se encontra o impasse da inclusão. Existe uma relação tênue e tensa entre o Um e o para todos, entre a Exceção e a regra. Santiago ainda nos adverte, que o apagamento do que individualiza um sujeito pode gerar efeitos que interferem, de maneira negativa, nas iniciativas, estratégias e resultados de programas de educação inclusiva (Santiago, 2018, p. 15).

A proposta educacional que as políticas públicas preconizam está sustentada no campo social, no que diz respeito ao acesso ao direito de estudar e ao dever do Estado em garantir educação para todos. Entretanto, quando falamos do sujeito autista, o que se observa é que ele está apoiado em um comportamento singular de ser. Como nos salientou Carbonell, o autista é um trabalhador incansável (Carbonell \& Ruiz, 2013, p. 115). Ele trabalha arduamente a fim de, minimamente, esvaziar-se de sua angústia. Dessa maneira, subverte as normaspadrão vigentes, pois, em suas atitudes, anula o excesso da presença do Outro, do qual o autista tenta se proteger.

Condizente a isso, a maneira de abordar e acolher as invençôes dos autistas na instituição escola deveria levar em consideração o conceito de sujeito, o qual a psicanálise propõe, para que, desse modo, a escola pudesse operar com os paradoxos do conceito de inclusão.

Para além da ideia de incluir o autista no programa escolar já formatado, a proposta advinda da psicanálise seria a de incluir a escola nas particularidades inventivas do sujeito. $\mathrm{O}$ autista não está na escola para ser reabilitado. $\mathrm{O}$ discurso pedagógico, quase sempre, está pautado no imperativo do ensino sistematizado para todos, não valorizando o saber do autista. $\mathrm{O}$ autista é um inventor do seu lugar no mundo e precisa minimamente ser ouvido por esse Outro escolar, para que sua inclusão de fato ocorra.

A escola deve apresentar-se de outra forma para com seus alunos, diferentemente de um dia azul e triste, como nos descreveu Tammet (2006), em seu livro Nascido em um dia azul. $\mathrm{O}$ ambiente escolar precisa estar atento às invenções dos autistas e perceber as nuances de suas diferenças, assim como Barnett (2013), o autista do livro Brilhante, viu nas frações de cores da luz no espectro de raio de sol que incidia sobre um copo.

A inclusão do diferente deve ir além da simples adequação dos conteúdos e flexibilização dos tempos escolares, cuidando para que não haja a segregação dos autistas em um canto da sala de aula ou da escola. A instituição escolar deve 
incluir a invenção do autista no seu plano de ensino e, assim, ela também estará inclusa nesse processo.

\section{SOBRE O DIAGNÓSTICO}

Quando Bleuler, em 1911, cunhou a palavra "autismo", Kanner, em 1943, recorreu a esse termo para distinguir seus casos clínicos dos casos de esquizofrenia infantil (apresentando como traços comuns a esse transtorno o desejo da solidão e a imutabilidade) (Kanner, 1997), o termo autismo se manteve estável por décadas, reaparecendo na primeira versão do DSM (Manual Diagnóstico e Estatístico dos Transtornos Mentais), em 1952. Na década de 1970, foi concebido o TEA com base em estudos genéticos.

Desde então, nunca se ouviu falar com tanta intensidade sobre o autismo como nos tempos atuais. Em graus diferenciados do diagnóstico, a classificação do TEA varia de grau severo do autismo até o nível dos sujeitos denominados Asperger.

Em seu artigo A psicopatia autística na infância, Asperger (1991) descreveu casos clínicos, relatando, com semelhança de detalhes, crianças com quadro de dificuldade na interação social, na comunicação e na capacidade interativa. Entretanto os autistas de Asperger apresentam uma memória privilegiada e não demonstram atraso nos aspectos cognitivos e da linguagem.

Assim, a classificação do autismo no CID-10 o diferencia da síndrome de Asperger, mesmo que os dois pertençam ao Transtorno Global do Desenvolvimento (TGD).

Este artigo vai apresentar um caso clínico de uma criança com o diagnóstico de síndrome do X-frágil. Esta é uma desordem ligada ao cromossomo X. É uma condição genética e hereditária, responsável por grande número de casos de deficiência mental e distúrbios do comportamento, podendo haver comorbidades. $\mathrm{Na}$ descrição do médico neurologista que atendeu a criança, estavam especificadas as seguintes características da síndrome: hipotonia global, incoordenação motora global, características autísticas (estereotipias, dificuldade no contato visual e socialização) e retardo mental. Essa síndrome se encaixa no autismo atípico, quadro em que o indivíduo parece autista, mas não se adéqua totalmente nos critérios estipulados. 


\section{O CASO K.}

O que o caso K. pode nos ensinar sobre o funcionamento autístico? É a partir dessa questão que iremos nos orientar para apresentar esse caso clínico. Pela análise dos acontecimentos relatados pretendemos demonstrar o que a prática contribuiu para a formalização da teoria.

Para tanto, nós nos debruçaremos na apresentação de um caso clínico que nomeamos de Caso K., em que buscaremos extrair da experiência vivenciada por uma professora do ensino fundamental, em uma turma de alfabetização, fragmentos, indícios que apontam a ideia do processo de aprendizagem de um autista. Pretendemos demonstrar como aconteceu a escolha de um duplo por esse aluno autista, como foi a ampliação da borda autística e o início da criação de um Outro à sua medida.

A criança, que chamaremos de K., ingressou em uma escola privada no ano de 2013, cursando o maternal 3. Filho de pais com formação superior, K. é o penúltimo filho de uma família de 4 irmãos. K. nasceu de cesariana, aos nove meses completos. Segundo relatos familiares, não necessitou de hospitalização e não teve outras complicações após o nascimento. Amamentou normalmente, e o pai relatou que, hoje em dia, K. tem um apetite avassalador. K. tem um ótimo relacionamento com os irmãos, que colaboram com seu desempenho na escola e em seu desenvolvimento social.

A primeira professora que K. teve contato foi a do maternal 3. Ela notou diferenças no comportamento da criança e alertou a coordenadora de ensino, solicitando uma reunião com a família. A princípio, a família ficou na defensiva e não aceitou que pudesse haver diferença no modo de ser do filho. Em virtude de alterações no desenvolvimento de K., os pais buscaram avaliações médicas. O diagnóstico foi dado em outubro de 2015: síndrome do X-frágil.

No Plano de Desenvolvimento Individual (PDI), feito pela professora do $2^{\circ}$ período, já no ano de 2016, encontramos informações a respeito do acompanhamento clínico de K. e das dificuldades motoras e da fala apresentadas por ele:

Passou por seções de Psicologia, Terapia Ocupacional e Fonoaudiologia no centro de saúde. Depois passou a ter atendimento particular com fonoaudióloga e terapeuta ocupacional. Apresenta muitas dificuldades de coordenação motora, tonicidade, mobilidade e equilíbrio. Apresenta também dificuldades de comunicação e linguagem oral. Consegue realizar jogos que utilizam a coordenação motora fina, mas tem dificuldade ao realizar o traçado das letras na escrita. 
Extraímos também do PDI de K. relatos dos pais sobre a sua interação social e seu comportamento:

Convive com outras crianças no prédio, demonstrando saber conviver, apesar de ter dificuldade em lidar com a própria frustração e também apresenta comportamento impulsivo, empurrando as outras crianças. Durante a alimentação, costuma usar as mãos ao invés dos talheres. Consegue tomar banho sozinho com comando verbal para finalizar as tarefas. Troca de roupa e calça o chinelo ao contrário, mas, quando orientado, consegue corrigir. Usa o banheiro sozinho, com pequenos intervalos, principalmente quando está mais ansioso. Nem sempre expressa com clareza a necessidade de fazer "xixi e cocô", por isso, às vezes, faz "cocô" na roupa logo após retornar do banheiro.

O corpo do autista não se inscreve no mesmo discurso que se espera de uma criança típica da sua idade. Ele permanece preso em seu gozo mortífero. Suportar a presença de outras crianças pode ser angustiante para ele e, para apaziguar essa angústia, age com impulsividade. Conseguir atuar sobre o seu corpo e obter um conhecimento demanda um esforço e um trabalho constante de compreensão desse gozo. É necessário que haja uma ligação libidinal com o entorno. Se não existe essa ligação extracorpórea, o sujeito não se anima a realizar tarefas simples.

Segundo o relato da professora que o atendeu anteriormente, percebemos a dificuldade que K. apresentava em compreender o espaço físico e limitar seus movimentos nesse espaço determinado. A professora exemplificou essa dificuldade por meio da realização de desenhos, pintura dentro de limites e fazer o traçado da letra. Ela enfatizou que a letra que ele aprendeu é a de imprensa maiúscula (caixa-alta), e os outros alunos já faziam a escrita da letra cursiva. Contudo K. realizou o movimento correto de pinça com o lápis, mas necessitou ser lembrado com frequência para manter o foco na atividade.

Com base nos relatos escolares, percebemos que o aluno K. marcava suas atividades escolares com a letra maiúscula de imprensa, que representava o seu nome. Para Maleval (2017), "Quer o signo seja sonoro, quer escritural, ele permanece por muito tempo manifestamente correlato a uma determinada experiência” (p. 249).

A noção de longe e perto, dentro e fora para um autista é diferente da noção espacial que temos. É uma topologia diferente da nossa. Perceber os limites de uma atividade definidos em uma folha de papel pode ser uma tarefa que impossibilita a compreensão do entorno para o autista.

A borda autística é uma formação protetora contra o Outro real ameaçador. A construção de uma borda é o que permite limitar o gozo. Ao mínimo empenho de ceder o gozo no campo do Outro, o deslocamento da borda pode acontecer. Se não há uma contenção do seu corpo para que ele se introduza no campo do 
Outro, não será possível a realização de uma simples tarefa. Assim, como dar cores ao desenho que a professora solicitou?

No ano de 2017, K. cursou o primeiro ano do ensino fundamental. Desde o primeiro dia de aula, a mãe chegou com um informativo a respeito da síndrome do X-frágil, vindo de um grupo de pais e pesquisadores ligados à UFMG. A mãe solicitou que ele sentasse perto da mesa. Deu algumas orientações sobre ida ao banheiro, alimentação e disse que ele não tomava nenhum medicamento. Despediu-se, meio desconfiada da nova situação que ele enfrentaria, e foi embora.

$\mathrm{K}$. demonstrou estar assustado e, por vezes, entrou debaixo de sua mesa até sentir-se confortável para socializar com os seus colegas. Metade da turma de 2017 era formada por colegas de sala do ano anterior. A novidade para K. passou a ser sua nova professora. As particularidades de K. foram aceitas e, aos poucos, incluiu a professora em suas atividades.

\section{A ESCOLHA DE UM DUPLO, A ESCRITA DA LETRA CURSIVA, A CONSTRUÇÃO DE UM OUTRO À SUA MEDIDA}

Havia uma grande expectativa, por parte dos pais, para que K. se desenvolvesse, saísse de sua condição autística e aprendesse como as outras crianças. Entendemos que o autista está imerso na linguagem. Lacan (apud Maleval, 2011), disse a respeito de Dick, paciente de Melanie Klein, que "Como ele não nos disse nada, não temos nenhum meio para penetrar ali”. A respeito disso, Lacan observa que Dick é um "mestre da linguagem", ao passo que se compromete em rechaçá-la para não ter a dor inerente, advinda da extração de sua voz (p. 99).

A estrutura autística de K. não lhe permitiu extrair o gozo vocal. De acordo com Maleval (2011, p. 96), ainda que o sujeito autista se defenda da linguagem, está submerso, desde antes de seu nascimento, em um banho verbal que o afeta.

Mencionamos, no início deste artigo, que a educação usa da palavra como ferramenta primordial de endereçamento de seus propósitos ao indivíduo. Por conseguinte, ela espera que o retorno da compreensão do que foi ensinado seja pela palavra.

Como entender a subjetividade do autista sem que ele convoque sua própria voz? Como penetrar, sem invadir, em um terreno desconhecido, passível de equívocos em suas significações?

O aluno quis aprender a escrever a letra cursiva. No início, escrevia com letra de forma maiúscula (caixa-alta). Na tentativa de ajudar o seu desenvolvimento, a professora dividiu o quadro da sala de aula, onde algumas atividades eram descritas. De um lado, usava a escrita 
cursiva para os demais alunos e, do outro lado, fazia a escrita em caixa-alta. Pouco tempo depois, percebendo a diferença entre as duas fontes apresentadas no quadro e no caderno dos colegas, o aluno demonstrou interesse na letra cursiva, como era ensinada para seus colegas (PDI de K.).

Para Maleval (2011, p. 96), a construção de uma realidade compatível com a dos demais passa por integrá-los à sua borda autística. A atitude de K. indica que ele deseja, minimamente, que as atividades escolares integrem seu espaço.

Por não ter domínio corporal, K. recorreu ao recurso do duplo para libidinizar seu corpo e, assim, permitir que seus movimentos para a execução da escrita da letra cursiva fossem alcançados. O duplo é um campo que permite que o sujeito fale com o Outro. Dessa maneira, K. nos indica que a estimulação de suas capacidades intelectuais está relacionada à elaboração de uma borda.

Faz-se necessário, portanto, criar um Outro sob medida, um Outro que pode encontrar, em uma nesga de abertura da borda autística, um espaço para, minimamente, inserir-se na vida do sujeito autista. É preciso fazer um furo na borda para que haja um trânsito no saber, para que seja estabelecido um circuito pulsional.

Em relação à leitura, para nós, ficou uma incógnita sobre a aquisição dessa habilidade. K. participou de atividades em sala de aula que o possibilitaram estar envolvido em várias situações de leitura: interpretação de gravura, identificação de letras, sílabas e palavras, compreensão do enunciado e leitura oral coletiva. Essas atividades produziram certa regulação sobre K., fazendo com que ele ficasse disposto a participar, exercendo, então, uma função educativa.

Encontramos, no PDI, passagens que apontam para uma estratégia de leitura encontrada por K.: ao ver, sobre a mesa da professora, os cadernos e livros de atividades de seus colegas, ele entregava corretamente para os seus colegas, identificando-os pelas letras iniciais de cada criança ou pela etiqueta que tinha um desenho específico em cada caderno, valendo-se de sua possível memória idética, em substituição da aprendizagem-padrão.

Quando essa aptidão é débil, o sujeito procura remediá-la retendo, um a um, todos os elementos considerados. É, por um lado, de uma dificuldade em desconectar a palavra da coisa que nasce a estimulação da memória do autista [. . . A A despeito dos limites em que o seu pensamento abstrato se choca, o recurso a procedimentos compensatórios pode torná-lo apto a desenvolver-se por meio de uma vagarosa intelectualização (Maleval, 2017, p. 246).

A mediação era feita oralmente e fisicamente. Para a escrita espontânea, perguntávamos com qual(is) letra(s) cada sílaba deveria ser escrita e, após sua 
resposta, ajudávamos a escrever, palavra por palavra. Caso errasse, mostrávamos o caminho certo. Carbonell, em sua obra No todo sobre el autismo, diz que a palavra, quando permite o ato de falar, serve às funções mais complexas da linguagem e da comunicação (Carbonell \& Ruiz, 2013).

K. foi constantemente auxiliado para que sua escrita se mantivesse dentro do espaço reservado para as atividades escolares. Entretanto todo o trabalho de escrita era mediado. Ao segurar a mão do aluno para a escrita, apenas guiávamos o seu traçado. O movimento era feito por ele (PDI de K.).

A palavra escrita em letra cursiva junta as letras, cria palavras. É preciso ter um corpo para poder fazer essa operação de aglutinar as letras e formar palavras. "É preciso 'grampear' o seu corpo e, assim, animá-lo libidinalmente" (Vidigal, 2019, Seminário de conversação: casuística contemporânea [IEC]). ${ }^{2}$

De acordo com Maleval (2011, p. 98), muitas crianças autistas, com a finalidade de evitar o compromisso que constitui uma chamada, que implica sempre o risco de ser rechaçado, preferem usar a mão de um adulto para conduzilo até efetuar uma ação que desejava.

O autista faz a concessão da entrada desse Outro se, e somente se, ele não lhe é ameaçador. É a construção de um Outro sob medida. Um Outro que apazigua e organiza o entorno.

Os autistas se percebem como seres inanimados e, para tanto, realizam tentativas com objetos e com pessoas para se sentirem humanos. A dinâmica da conexão com o mundo se dá por seu duplo protetor, assim como sua enunciação também pode se dar por meio desse duplo. Para Maleval (2011), o duplo se impóe ao autista como uma estrutura privilegiada para sair da sua solidão. É uma estrutura apaziguadora, pois é construída por ele mesmo, um duplo à sua medida e está "apta para receber um gozo emoldurado, uma estrutura em que pode apoiar-se" (Maleval, 2011, p. 99).

Graças ao tratamento do gozo, mediante o apoio de seu duplo, K. pôde aprender a escrita da letra cursiva sem a angústia de ter um corpo desmantelado, pois o outro à sua medida se encontrava à sua disposição. Maleval (2017) descreve como os autistas de alto funcionamento Grandin, Williams, Barron e Tammet compensaram a dificuldade de representar no campo da linguagem: a expressão oral da intimidade deles permanece difícil, mas passando pelo escrito (às vezes, com a ajuda de um facilitador, jornalista ou parente próximo), chegam a contornar obstáculos e a relatar isso (Maleval, 2017, p. 255). K. consentiu em

2 Anotaçôes extraídas do "Seminário de conversação: casuística contemporânea", com a Prof.a C. Vidigal, no Curso de PósGraduação Abordagem Psicanalítica do Autismo e suas Conexões - IEC, 27 de abril de 2019. 
conectar-se à imagem protetora e pacificadora do duplo e, desse vínculo, extrair os benefícios imediatos.

Concordamos com o conceito que assegura que o autismo evolui na direção do autismo. K. não demonstrou a escrita ortográfica perfeita nem mesmo permitiu a extração de sua voz para que demonstrasse sua prática de leitura. Contudo se mostrou atento às atividades apresentadas. Consentiu fazer parte do grupo. Tinha orgulho em fazer a letra cursiva com a mesma postura de estudante de seus colegas.

Assim como Williams (apud Maleval, 2011) descreve sua maneira de falar com o Outro, acreditamos que também essa pode ter sido a estratégia usada por K. para se inscrever na prática da linguagem: "Seu discurso não é destinado diretamente ao interlocutor - o que quer dizer que ela falará por intermédio de objetos, ou seja, com os próprios objetos (compreendida aí a escrita, que é uma forma de falar por intermédio do papel)" (Maleval, 2011, p. 97).

\section{CONSIDERAÇÕES FINAIS}

A articulação constante entre o que norteia a teoria psicanalítica de orientação lacaniana e o que nos demonstra, nas pequenas sutilezas do Caso K., que foi discutido, nos faz considerar a urgência de uma articulação entre educação e psicanálise. É necessário que o processo de inclusão no sistema educacional se amalgame a um discurso teórico que o oriente e o insira, de maneira que a escola não se sinta excluída. $\mathrm{O}$ caso $\mathrm{K}$. revela o quanto essa criança autista tem a ensinar a respeito de sua maneira de reinventar o mundo. Um mundo à sua medida.

$\mathrm{O}$ intuito de incorporar a psicanálise no campo pedagógico é o de fazer a palavra circular. Promover conversações entre os profissionais da educação, permitindo que compartilhem e debatam sobre assuntos similares, ações efetivas e proporcionar mudanças.

A psicanálise não propõe homogeneizar os discursos pedagógicos ou generalizar as questôes presentes no interior de cada escola. Ela permite que o professor se dispa do seu saber, reduzindo a consistência da palavra do mestre como a única possível. Dessa maneira, acreditamos que o singular possa aparecer, que o Um passe a ter voz, mesmo sendo um sujeito preso ao seu gozo vocal.

Para finalizarmos, refletimos a respeito do trabalho de educação inclusiva nas instituiçôes escolares: desprender-se das rotulaçôes, da busca de um nome para identificar um sujeito autista é um caminho para dissolver os impasses da educação inclusiva. 
Entendemos que, embora o aluno tenha adquirido habilidades relacionadas à leitura de palavras e pequenos textos, a dissociação entre voz e linguagem permanece, assim como o excesso do gozo, o que interfere na comunicação.

Em todos os níveis de evolução do autismo persiste, em graus diversos, um mesmo transtorno: a extrema dificuldade, não de adquirir a linguagem, mas de tomar uma posiçãao de enunciação. Uma vez que a linguagem não é investida pelo gozo vocal, ela é inicialmente vivenciada por esses sujeitos como um objeto sonoro que eles não percebem que serve para a comunicação (Maleval, 2011, p. 102).

Sabemos que ele identificou as letras e relacionou os sons. Verbalizou monossílabo por monossílabo e, pelo recurso do duplo, fez leitura simples. Por isso acreditamos que ele, minimamente, a seu modo, para além dos manuais pedagógicos, encontra-se dentro do processo de alfabetização e aquisição da leitura. "Quando um autista se estrutura - graças a uma terapia ou um trabalho educativo -, em geral se observa que os seus transtornos sensoriais melhoram de maneira considerável" (Maleval, 2017, p. 254).

Concordamos com Maleval quando aponta a diversidade de construir uma possibilidade única de aprendizagem do sujeito autista. O lugar de enunciação faz parte de todo o processo educativo, do ensino fundamental à universidade, não somente do sujeito autista, em que a posição estrutural, à primeira vista, pode ser um impeditivo. Contudo o autista, em seu constante trabalho, lança mão do duplo, dos objetos e da borda para contornar os obstáculos e construir uma possibilidade de aprendizagem. 


\section{REFERÊNCIAS}

Asperger, H. (1991). Autistic psychopathy in childhood. In U. Frith (Ed.), Autism and Asperger syndrome (pp. 37-92). Londres: Cambridge University Press. (Publicado originalmente em 1944).

Barnett, K. (2013). Brilhante: a inspiradora história de uma mãe e seu filho gênio e autista. Rio de Janeiro: Jorge Zahar.

Carbonell, N., \& Ruiz, I. (2013). No todo sobre el autismo. Madrid: Gredos.

Constituição da República Federativa do Brasil (1988). (1988). Brasílias: Supremo Tribunal Federal. Recuperado a partir de http://www.stf.jus.br/arquivo/cms/legislacaoConstituicao/anexo/CF.pdf

Freud, S. (1925/1980). Prefácio à "Juventude Desorientada", de Aichhorn. In J. Salomão (Trad.), Edição standard brasileira das obras psicológicas completas de Sigmund Freud. (Vol. 19, pp. 337-343). Rio de Janeiro: Imago, 1980. (Publicado originalmente em 1925).

Freud, S. (1929/1981). O mal-estar na civilização. In Obras completas. (Vol. 3). Madrid: Editorial Biblioteca Nueva, 1981. (Publicado originalmente em 1929).

Freud, S. (1937/1980). Análise terminável e interminável. In J. Salomão (Trad.), Edição standard brasileira das obras psicológicas completas de Sigmund Freud. (Vol. 23, pp. 239-287). Rio de Janeiro: Imago, 1980. (Publicado originalmente em 1937).

Kanner, L. (1997). Os distúrbios de contato afetivo. In P. S. Rocha (Org.), Autismos. (pp. 111-170). São Paulo: Escuta.

Lei no 9.394, de 20 de dezembro de 1996. (1996, 20 dezembro). Estabelece as diretrizes e bases da educação nacional. Diário Oficial da União, Brasília. Recuperado a partir de http://www.planalto.gov.br/ccivil_03/leis/19394.htm

Maleval, J-C. (2011). El autismo y su voz. Madrid: Gredos.

Maleval, J-C. (2017). O autismo e a sua voz. São Paulo: Blucher.

Perez, J. F. (2012). Impossibilidade. In O. Machado, \& V. L. A. Ribeiro (Orgs.). Scilicet: a ordem simbólica no século XXI. (pp. 202-202). Belo Horizonte: Scriptum. 
Santiago, A. L. (2018). O que esse menino tem?: sobre alunos que não aprendem e a intervenção da psicanálise na escola. Belo Horizonte: Relicário.

Tammet, D. (2006). Nascido em um dia azul. Rio de Janeiro: Intrínseca.

Teperman, D. (2014). Tratamentos possíveis ao impossível da educação. Estilos da Clínica, 19(3), 515-518. Recuperado a partir de https://dx.doi.org/10.11606/issn.1981-1624.v19i3p515-518

Yanet, L. (2018). O império do Um: diálogo com educadores a propósito da educação inclusiva. Lacan XXI - Revista Fapol, 1. Recuperado a partir de http:/www.lacan21.com/sitio/2018/05/04/o-imperio-do-um-dialogo-comeducadores-a-proposito-da-educacao-inclusiva-1/?lang=pt-br 